\title{
Intestinal microbiota and active systemic lupus erythematosus: a systematic review
}

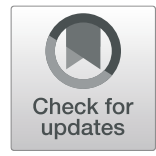

Juliana Rosa Pires Vieira ${ }^{1}$, Andréa Toledo de Oliveira Rezende ${ }^{1 *}$ (D) Marcos Rassi Fernandes ${ }^{1,2}$ and Nilzio Antonio da Silva ${ }^{1,3}$

\begin{abstract}
Background: Systemic Lupus Erythematosus (SLE) is an autoimmune disease, characterized by being multi-systemic and, therefore, reaching various organs and affecting mainly young women. Its pathogenesis comprehends many factors, including the interaction between microbiota and immune system. This systematic review assessed the relationship between intestinal microbiota and SLE in activity, highlighting microbiota representative patterns regarding quantity and diversity.

Methods: This study considered researches carried out in patients with SLE, with no restriction of age or gender, which fulfilled the classification criteria of either Systemic Lupus International Collaborating Clinic (SLICC), American College of Rheumatology (ACR) or European League Against Rheumatism (EULAR) and used the Systemic Lupus Erythematosus Disease Activity Index (SLEDAI) to classify disease in activity or remission were included. The search was carried out from October, 2020 to January, 2021 using the following databases: Medline via Pubmed, Scopus, and Embase. Five papers were included with a total of 288 participants with SLE.

Results: Regarding microbiota in patients with SLE in activity, there was significant increase in the following genera: Lactobacillus, Streptococcus, Megasphaera, Fusobacterium, Veillonella, Oribacterium, Odoribacter, Blautia, and Campylobacter. On the other hand, decrease in Faecalibacterium and Roseburia genera as well as Ruminococcus gnavus species was observed in remission cases, showing differences between the microbiota profile in SLE in activity and in remission.
\end{abstract}

Conclusions: Results suggest that dysbiosis may be involved in the disease activity process.

Trial registration: CRD42021229322.

Keywords: Microbiota, Systemic lupus erythematosus, Inflammation, Dysbiosis, SLE

\section{Introduction}

Systemic Lupus Erythematosus (SLE) is an autoimmune, chronic, and multi-systemic disease that affects mainly young women [1]. This condition has as main feature intolerance to autoantigens [2] resulting in numerous antibodies and inflammatory recruitment of $\mathrm{T}$ cells, producing pro-inflammatory cytokines [3].

\footnotetext{
* Correspondence: rezende.andrea@hotmail.com

${ }^{1}$ Postgraduate Program in Health Sciences, School of Medicine of the Universidade Federal de Goiás (UFG), Goiânia, Brazil

Full list of author information is available at the end of the article
}

The cause of SLE is unknown, however its predisposing factors are: (a) genetic, e.g. CSK and IRF7 genes; (b) immune, comprehending the production of B cells that produce antibodies and $\mathrm{T}$ cells; and (c) hormonal, related to estrogen increase. Additionally, environmental and/or psychological factors are also triggers, such as sunlight exposure, drugs, intestinal microbiota, EpsteinBarr virus, cytomegalovirus, smoking, sedentary lifestyle, and stress [4-8].

Among the abovementioned factors, intestinal microbiota plays a fundamental role in metabolic function, epithelium barrier maintenance, immune system

(c) The Author(s). 2021 Open Access This article is licensed under a Creative Commons Attribution 4.0 International License, which permits use, sharing, adaptation, distribution and reproduction in any medium or format, as long as you give appropriate credit to the original author(s) and the source, provide a link to the Creative Commons licence, and indicate if changes were made. The images or other third party material in this article are included in the article's Creative Commons licence, unless indicated otherwise in a credit line to the material. If material is not included in the article's Creative Commons licence and your intended use is not permitted by statutory regulation or exceeds the permitted use, you will need to obtain permission directly from the copyright holder. To view a copy of this licence, visit http://creativecommons.org/licenses/by/4.0/. 
modulation and homeostasis, as well as protection against infection by pathogenic agents. On the other hand, intestinal balance is preserved by a complex cellular network that acts on the development of innate and adaptive immune response [9].

Therefore, intestinal microbiota may be important on the development and maintenance of SLE symptoms [6]. Immune responses against intestinal microorganisms could exacerbate preexistent inflammation and imbalance of intestinal regulating $\mathrm{T}$ cells (Treg/Th17), which could attack intestinal microbiota and amplify dysbiosis. This process leads to a vicious cycle in which the disease states continues [9].

In view of that, it is necessary an in-depth study for better understanding the role of intestinal microbiota in SLE etiopathogenesis and activity, focusing on the following questions: (a) does intestinal microbiota present distinctive characteristics, assessed by quantity and diversity, in patients with SLE in activity?; (b) is there dysbiosis in the microbiota of SLE in activity?; (c) is the pattern of intestinal bacteria different in SLE in activity and SLE in remission?

It is important to highlight that this is the first systematic review addressing the relationship between microbiota and active SLE. In this context, this paper aimed to verify whether there is a relationship between intestinal microbiota composition and SLE activity. The hypothesis is that there are representative patterns and dysbiosis in the microbiota composition of patients with SLE in activity, distinct of those from SLE patients in remission.

\section{Methods}

This study was conducted and reported in line with the Preferred Reporting Items for Systematic Reviews and Meta-Analyses (PRISMA) [10]. The review adopted the PECO structure (Population, Exposure, Comparator, and Outcome) recommended for systematic reviews [11]. The PECO structure was defined as 'P' (patients with SLE), 'E' (intestinal microbiota composition), 'C' (SLE in remission and healthy control group), and ' $\mathrm{O}$ ' (SLE in activity). This systematic review was registered with the International Prospective Register of Systematic Reviews (PROSPERO) [12] under number CRD42021229322.

\section{Eligibility criteria}

This review included observational studies (cross-sectional, cohort, and case-control) which analyzed the intestinal microbiota composition in patients with SLE. Publications concerning cases with SLE, with no restriction of age or gender, which fulfilled the classification criteria of either Systemic Lupus International Collaborating Clinic (SLICC) [13], European League Against
Rheumatism (EULAR) or American College of Rheumatology (ACR) [14] and considered the Systemic Lupus Erythematosus Disease Activity Index (SLEDAI) [15] to classify disease in activity or in remission were included. Researches that used only animals were excluded, however studies which included both animals and SLE patients were considered, and it is important to highlight that this review described only data from humans. Studies that assessed composition of microbiota based on stool sample using culture-dependent methods either real-time polymerase chain reaction (PCR), fluorescence in situ hybridization (FISH) or pyrosequencing for bacterial $16 \mathrm{~S}$ ribosomal ribonucleic acid (rRNA) genes were considered. There was no restriction on language and publication year.

Ecological studies, case reports or case series, literature reviews, randomized clinical trials, dissertation, thesis and conference summaries, as well as duplicate articles and unavailable data even after contacting the authors were excluded. Researches in patients with intestinal and metabolic diseases that somehow affect intestinal microbiota, in addition to articles that did not provide measures for microbiota composition were also be excluded.

\section{Databases}

Searches were carried out from October, 2020 to January, 2021 using the following databases: Medline via Pubmed, Scopus, and Embase. The search strategy applied MeSH terms in PubMed, Emtree terms in Embase, and both terms in Scopus. Relevant keywords about SLE and microbiota were also used, aiming to encompass all articles on this issue.

The search was adapted for each database, and the following strategy was used in Pubmed:

1. = "lupus erythematosus, systemic" [MeSH] OR "systemic lupus erythematosus" OR "lupus erythematosus disseminates"

2. = microbiota $[\mathrm{MeSH}]$ OR microbiotas OR "microbial community" OR "community, microbial" OR "microbial communities" OR "microbial community composition" OR "community composition, microbial" OR "composition, microbial community" OR "microbial community compositions" OR "microbial community structure" OR "community structure, microbial" OR "microbial community structures" OR microbiome OR microbiomes OR "human microbiome" OR "human microbiomes" OR "microbiome, human

3. = dysbiosis $[\mathrm{MeSH}]$ OR recurrence $[\mathrm{MeSH}] \mathrm{OR}$ "severity of Illness Index"[MeSH] OR relapse OR "disease severity"

4. = 1 AND 2 AND 3 


\section{Review process}

The search was performed by two independent researchers (JRPV and ATOR), who grouped the articles and deleted the duplicated ones using Mendeley software. Then, these researchers individually selected the articles using Rayyan software, afterwards read the titles, the abstracts and, finally, the entire article, according to the eligibility criteria, and so articles were included. Disagreements about inclusion were discussed and resolved by a third senior reviewer (MRF).

\section{Data extraction}

In order to assess the risk of bias, Downs \& Black Scale [16] was used, it consists of an instrument with 27 items, however only 16 items are applicable to observational studies (questions 1-3, 5-7, 9-12, 17, 18, 20, 21, 25, 26). This systematic review was based on the following aspects: a) objective clearly stated; b) main outcomes clearly described; c) sample characteristics clearly defined; d) distribution of principal confounders clearly described; e) main findings clearly defined; f) random variability in estimates provided; g) losses to follow-up described; h) probability values reported; i) sample target representative of population; j) sample recruitment representative of population; k) analyses adjusted for different follow-up duration; l) statistical tests appropriately used; m) accurate primary outcomes; $n$ ) patient sample recruited from the same population; o) adequate adjustment for confounders; and p) losses of sample to followup considered. The punctuation was applied for each manuscript according to the number of items considering the total percentage ( 0 to 17 points ${ }^{1}$ ). Low bias risk was defined as total score $>70 \%$.

The Grading of Recommendations, Assessment, Development, and Evaluation (GRADE) [17] was applied to assess the quality of the evidence of the selected studies. For each study, the quality was ultimately assigned one of the following four grades: high quality (four filled circles), moderate quality (three filled circles), low quality (two filled circles), or very low quality (one filled circle). Following this approach, observational studies were lower (beginning with two circles), some items may compromise the quality of evidence, such as: risk of bias, imprecision, inconsistency, indirectness, and publication bias. Conversely, the quality of evidence may increase (additional filled circles) when the effects are sufficiently relevant, when all plausible biases would underestimate the effect, or when a doseresponse gradient is present [18].

Data were extracted from articles that presented information related to intestinal microbiota and SLE in activity or remission and, then, they were inserted in a

\footnotetext{
${ }^{1}$ Item number 5 can present two scores.
}

standardized form prepared by the authors. The following aspects were considered: author, year/country where the study was carried out, type of study, participants, microbiota analysis method, SLEDAI cut-off score $\geq 8$ was used to define active SLE, and outcomes.

\section{Results}

The search resulted in 500 papers, out of which 327 were duplicates, 146 titles did not include the terms 'microbiota' and 'SLE', and 12 abstracts were not related to the subject. Subsequently, ten papers were eliminated after being read entirely as they did not meet the eligibility criteria. Therefore, five papers were selected for the systematic review (Fig. 1).

These papers were considered as low bias risk, three of them scored $80 \%$ at Downs \& Black Scale while the remaining two papers received a score of $76 \%$. In relation to GRADE, two papers obtained moderate quality and the other three, low quality. The individual results of the studies can be found in (Table 1).

The total number of participants considering the five studies was 530, out of which 195 had SLE in activity, 93 SLE in remission, and 222 healthy controls. Concerning participants' gender, two studies considered both genders and three studies prioritized female. Regarding the country where they were carried out, three are from China [19-21], one from the United States [7], and one from Spain [3]. All of them used DNA extraction in stool samples through RNAr $16 \mathrm{~S}$ sequencing as analysis method of fecal microbiota (Table 2).

Either SLICC, EULAR or ACR classification criteria were applied in all of the researches as well as SLEDAI, which was applied to assess the disease activity index. Concerning the type of study, two of them was crosssectional and three was cohort.

Three of the studies were focused on the relationship between microbiota and SLE in activity, one focused on microbiota of SLE in remission, and one focused on both.

With respect to intestinal microbiota composition and its main characteristics in patients with SLE in activity, studies highlighted greater amount of bacteria from the following genera: Lactobacillus (Lactobacillus mucosae species) [7, 21], Streptococcus (Streptococcus anginosus species), Megasphaera, Fusobacterium, Veillonella (Veillonella dispar species), Oribacterium [21], Odoribacter [7], and Blautia (Lachnospiraceae family) [7, 19]. Besides, Streptococcus and Campylobacter genera standed out as positively correlated with SLEDAI [7, 21].

Regarding phyla, high level of Proteobacterias (Epsilonproteobacteria class, Campylobacterales order and Campylobacter genus) [20, 7], Bacteroidetes (Prevotella genus), and Actinobacteria (Rhodococcus and Eggerthella 


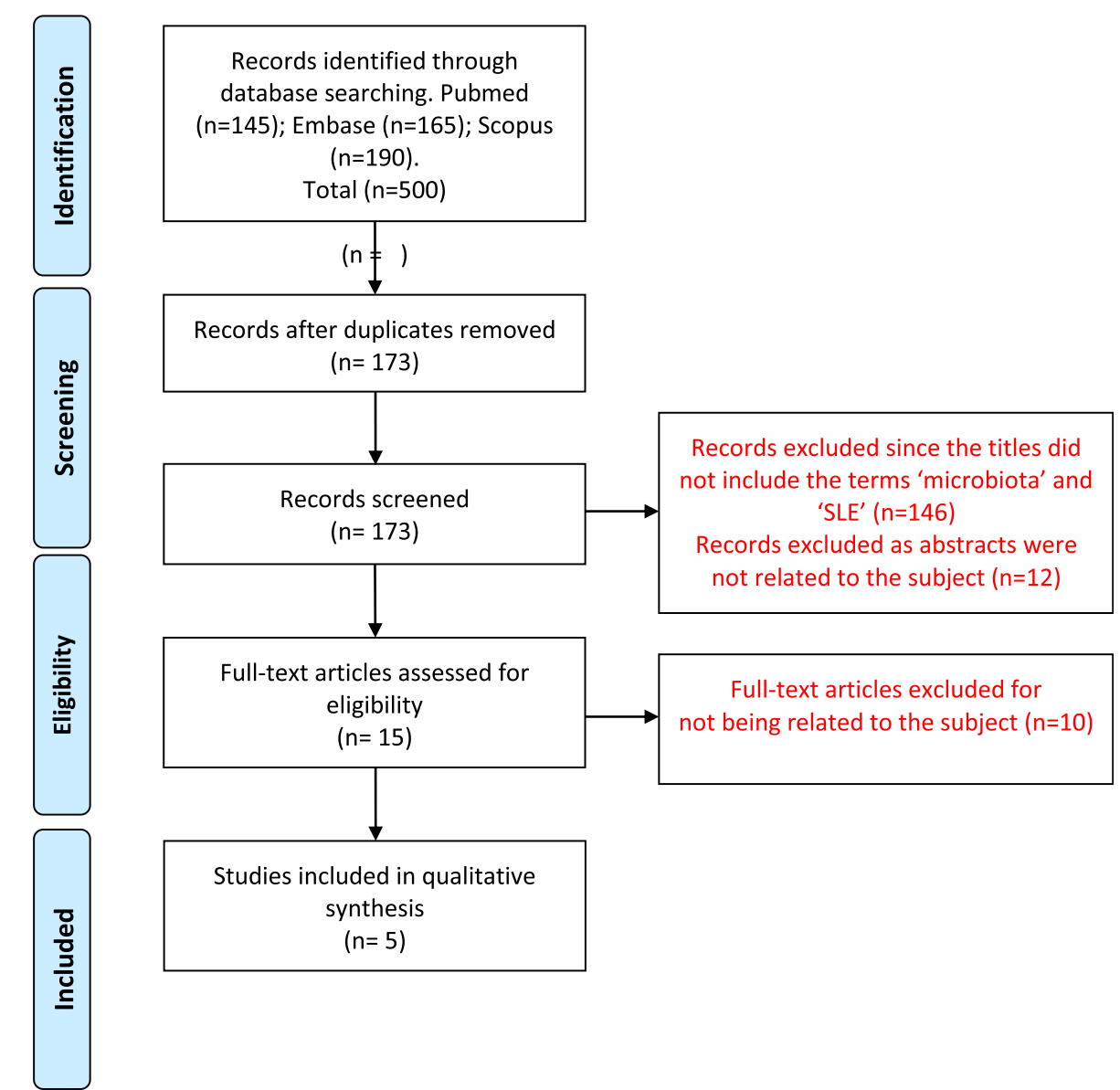

Fig. 1 PRISMA Flow Diagram of search and study selection

Table 1 Methodological quality assessment and strength of evidence

\begin{tabular}{|c|c|c|c|c|c|c|c|c|c|c|c|c|c|c|c|c|c|c|c|c|c|}
\hline \multirow[t]{2}{*}{ Study (year) } & \multirow{2}{*}{$\begin{array}{l}\text { Conflict } \\
\text { of } \\
\text { Interests }\end{array}$} & \multirow{2}{*}{$\begin{array}{l}\text { Ethical } \\
\text { Approval }\end{array}$} & \multicolumn{18}{|c|}{ Downs and Black checklist } & \multirow[t]{2}{*}{ GRADE } \\
\hline & & & $\bar{A}$ & B & C & D & $E$ & $F$ & G & $\mathrm{H}$ & $I$ & $J$ & $\mathrm{~K}$ & $\mathrm{~L}$ & $M$ & $\mathbf{N}$ & 0 & $\mathbf{P}$ & Total & Score $^{\#}$ & \\
\hline Chen at al. 2020 & No & Yes & 1 & 1 & 1 & 0 & 1 & 1 & 1 & 1 & 1 & 1 & 1 & 1 & 1 & 1 & 0 & 1 & 14 & $80 \%$ & \\
\hline He at al. 2016 & No & Yes & 1 & 1 & 1 & 0 & 1 & 1 & - & 1 & 1 & 1 & 1 & 1 & 1 & 1 & 0 & - & 12 & $80 \%$ & \\
\hline Li at al. 2019 & No & Yes & 1 & 1 & 1 & 0 & 1 & 1 & 1 & 1 & 1 & 1 & 1 & 1 & 1 & 1 & 0 & 1 & 14 & $80 \%$ & \\
\hline Luo at al. 2018 & No & * & 1 & 1 & 1 & 0 & 1 & 1 & 1 & 1 & 1 & 1 & 1 & 1 & 1 & 0 & 0 & 1 & 13 & $76 \%$ & \\
\hline Hevia at al. 2014 & $*$ & Yes & 1 & 1 & 1 & 0 & 1 & 1 & _ & 1 & 1 & 1 & _- & 1 & 1 & _ & 0 & _ & 10 & $76 \%$ & \\
\hline
\end{tabular}

Downs and Black checklist: A) objective clearly stated; B) main outcomes clearly described; C) sample characteristics clearly defined; D) distribution of principal confounders clearly described; E) main findings clearly defined; F) random variability in estimates provided; G) lost to follow-up described; $\mathrm{H}$ ) probability values reported; I) sample target representative of population; J) sample recruitment representative of population; K) analyses adjusted for different follow-up duration; L) statistical tests appropriately used; M) primary outcomes valid/reliable; N) sample recruited from the same population; $\mathrm{O}$ ) adequate adjustment for confounding; and $\mathrm{P}$ ) losses of sample to follow-up taken into account (corresponding to questions $1-3,5-7,9-12,17,18,20,21,25,26)$. Questions $G$ and $P$ were applied only for longitudinal studies. Questions $\mathrm{K}$ and $\mathrm{N}$ were applied only for case-control and longitudinal studies

\# Score reaches $100 \%$ with 13,15, and 17 points for cross-sectional, case-control, and longitudinal studies, respectively

*, not reported, - , not applied

GRADE, Grading of Recommendations, Assessment, Development and Evaluations; one filled circle, very low quality; two filled circles, low quality; three filled circles, moderate quality; four filled circles, high quality 
Table 2 Characteristics of the studies included in the systematic review

\begin{tabular}{|c|c|c|c|c|c|c|}
\hline $\begin{array}{l}\text { Author/ } \\
\text { year } \\
\text { Location }\end{array}$ & $\begin{array}{l}\text { Type of } \\
\text { Study }\end{array}$ & Participants & Gender & $\begin{array}{l}\text { Method of } \\
\text { Microbial } \\
\text { Analysis }\end{array}$ & $\begin{array}{l}\text { SLEDAI cut-off } \\
\text { score used to } \\
\text { define active } \\
\text { SLE }\end{array}$ & Results \\
\hline $\begin{array}{l}\text { Chen } \\
\text { et al. } \\
2020 \\
\text { China }\end{array}$ & $\begin{array}{l}\text { prospective } \\
\text { cohort }\end{array}$ & $\begin{array}{l}117 \text { patients with untreated } \\
\text { SLE, } 52 \text { patients with SLE } \\
\text { post-treatment; } 115 \text { healthy } \\
\text { controls. }\end{array}$ & $\begin{array}{l}\text { Female } \\
\text { and } \\
\text { Male }\end{array}$ & $\begin{array}{l}\text { DNA of stool } \\
\text { samples using } \\
\text { RNAr } 16 \mathrm{~S} \\
\text { sequencing }\end{array}$ & Not informed & $\begin{array}{l}\text { - Disease activity and microbial diversity } \\
\text { decreased significantly after treatment. } \\
\text { - } \downarrow \text { microbial richness and uniformity in } \\
\text { untreated SLE compared with control group. } \\
\text { - Seven species of markers enriched in } \\
\text { patients with untreated SLE and reduced } \\
\text { after treatment. } \\
\text { - Post-treatment microbial composition is more } \\
\text { similar to that in control group. }\end{array}$ \\
\hline $\begin{array}{l}\text { He et al. } \\
2016 \\
\text { China }\end{array}$ & $\begin{array}{l}\text { cross- } \\
\text { sectional }\end{array}$ & $\begin{array}{l}45 \text { patients untreated SLE } \\
\text { and } 48 \text { healthy controls }\end{array}$ & Female & $\begin{array}{l}\text { DNA of stool } \\
\text { sample using } \\
\text { RNAr } 16 \mathrm{~S} \\
\text { sequencing }\end{array}$ & Not informed & $\begin{array}{l}\cdot \uparrow \text { phyla: Bacteroidetes, Actinobacteria and } \\
\text { Proteobacteria. } \\
\cdot \downarrow \text { phyla: Firmicutes in individuals with } \\
\text { untreated SLE. }\end{array}$ \\
\hline $\begin{array}{l}\text { Li et al. } \\
2019 \\
\text { China }\end{array}$ & $\begin{array}{l}\text { prospective } \\
\text { cohort }\end{array}$ & $\begin{array}{l}19 \text { patients with SLE in } \\
\text { activity, } 21 \text { in remission, and } \\
22 \text { healthy controls. }\end{array}$ & Female & $\begin{array}{l}\text { DNA of stool } \\
\text { sample using } \\
\text { RNAr } 16 \mathrm{~S} \\
\text { sequencing }\end{array}$ & $\begin{array}{l}\text { Active SLE } \\
\text { patients: SLEDAI } \\
\geq 8\end{array}$ & $\begin{array}{l}\text { - Dysbiosis and constitution of microbial } \\
\text { community was different in SLE in activity } \\
\text { and SLE in remission, however, microbial } \\
\text { diversity is the same. } \\
\text { - } \downarrow \text { Bifidobacterium genus and } \\
\text { Ruminococcus.gnavus species in active SLE } \\
\text { when compared with SLE in remission. } \\
\text { - } \uparrow \text { six genera }{ }^{2} \text { as well as Proteobacteria } \\
\text { phylum in SLE in activity compared to } \\
\text { healthy controls. } \\
\text { - Lactobacillus genus associated with more } \\
\text { serious diseases. }\end{array}$ \\
\hline $\begin{array}{l}\text { Luo et al. } \\
2018 \\
\text { USA }\end{array}$ & $\begin{array}{l}\text { prospective } \\
\text { cohort }\end{array}$ & $\begin{array}{l}14 \text { patients with SLE in } \\
\text { activity and } 17 \text { healthy } \\
\text { controls }\end{array}$ & $\begin{array}{l}\text { Female } \\
\text { and } \\
\text { Male }\end{array}$ & $\begin{array}{l}\text { DNA of stool } \\
\text { sample using } \\
\text { RNAr } 16 \mathrm{~S} \\
\text { sequencing }\end{array}$ & $\begin{array}{l}\text { Active SLE } \\
\text { patients: SLEDAI } \\
\geq 8\end{array}$ & $\begin{array}{l}\text { - } \downarrow \text { microbial diversity in SLE in activity. } \\
\text { - Proteobacteria phylum, } \uparrow \text { Odoribacter and } \\
\text { Blautia genera and an unnamed genus } \\
\text { (Rikenellaceae family) in SLE in activity. } \\
\text { - Firmicutes and Bacteroidetes ratios did not } \\
\text { differ in microbiota between SLE and non- } \\
\text { SLE. }\end{array}$ \\
\hline $\begin{array}{l}\text { Hevia } \\
\text { et al. } \\
2014 \\
\text { Spain }\end{array}$ & $\begin{array}{l}\text { cross- } \\
\text { sectional }\end{array}$ & $\begin{array}{l}20 \text { patients with SLE in } \\
\text { remission and } 20 \text { healthy } \\
\text { controls }\end{array}$ & Female & $\begin{array}{l}\text { DNA of stool } \\
\text { sample using } \\
\text { RNAr } 16 \mathrm{~S} \\
\text { sequencing }\end{array}$ & $\begin{array}{l}\text { Active SLE } \\
\text { patients: SLEDAI } \\
\geq 8\end{array}$ & $\begin{array}{l}\text { - Dysbiosis in SLE in activity compared to SLE } \\
\text { in remission } \\
\text { - } \uparrow \text { three genera }{ }^{3} \text { and Bacteroidetes phylum, } \\
\downarrow \text { Firmicutes ratio in patients with SLE in } \\
\text { remission. } \\
\cdot \uparrow \text { Lachnospiraceae and Ruminococcaceae in } \\
\text { healthy controls }\end{array}$ \\
\hline
\end{tabular}

$\uparrow$ greater quantity or enrichment

$\downarrow$ lower quantity or depleted

Notes: ${ }^{1}$ Clostridium sp. ATCC BAA-442, Atopobium rimae, Shuttleworthia satelles, Actinomyces massiliensis, Bacteroides fragilis, Clostridium leptum, and one non-classified Escherichia.

${ }^{2}$ Lactobacillus, Streptococcus, Megasphaera, Fusobacterium, Veillonella and Oribacterium.

${ }^{3}$ Dialister, Pseudobutyrivibrio, and Bifidobacterium.

genera) was observed in patients with SLE who were not treated [19].

Seven markers species enhanced in patients with untreated SLE and which were reduced after treatment were found: Clostridium sp. ATCC BAA-442, Atopobium rimae, Shuttleworthia satelles, Actinomyces massiliensis, Bacteroides fragilis, Clostridium leptum, and nonclassified Escherichia [19]. Furthermore, some species are positively correlated with SLEDAI, such as: Ruminococcus torques, Lactobacillus salivarius [19], Lactobacillales [21], and Clostridium sp. ATCC BAA-442 [19]. However, healthy controls presented greater quantity of Lachnospiraceae and Ruminococcaceae families [3].
Considering bacteria found in reduced amount in SLE in activity, those belonging to Tenericutes and Mollicutes phyla, Faecalibacterium (prausnitzii), Roseburia, Bifidobacterium genera, and Ruminococcus gnavus species [21] are mentioned. Decrease in Firmicutes phylum as well as Pseudobutyrivibrio and Dialister genera [20] was observed in patients with untreated SLE.

Focusing on the dysbiosis issue, researches highlighted that microbial richness and uniformity was reduced in SLE in activity, although the number of species was maintained [19]. Besides, there was decrease in diversity after treatment and SLEDAI reduction [19]. However, it was observed that diversity and species metrics were 
significantly higher in healthy controls than in patients with SLE in activity [21].

Concerning the microbiota of patients with SLE in remission, attenuation in ratio Firmicutes/Bacteroidetes was inferred, with decrease of Firmicutes and increase of Bacteroidetes considering the overall bacterial level [3]. Exacerbated amount of Dialister, Pseudobutyrivibrio, and Bifidobacterium genera was also verified [3]. Differences in the microbial community constitution were observed between SLE in activity and in remission, such as Bifidobacterium genus increased in stool samples from patients with SLE in remission compared with those in activity [21]. Besides, Ruminococcus gnavus species was reduced, while Streptococcus, Lactobacillales de Bacillie, and Streptococcus anginosus species were enriched in patients with SLE in activity when compared with the group in remission. However, both groups were similar regarding diversity [21].

\section{Discussion}

This is the first systematic review that verified whether there is a relationship between intestinal microbiota composition and SLE in activity considering representative patterns, dysbiosis, and heterogeneity in active and in remission clinical conditions. This study evidenced particular characteristics in microbial profile in patients with SLE in activity, presenting different aspects when compared with those in remission. It was also noticed that there is intestinal dysbiosis, especially in SLE in activity.

Considering bacterial genera that were positively correlated with SLE in activity, pro-inflammatory bacteria were highlighted, such as Streptococcus, Megasphaera [21] as well as heterogeneity of intestinal microbiota. It was observed that bacterial diversity was reduced [21] in relation to microbial richness and uniformity, but not in relation to the number of species [19] . This supports studies that reported pro-inflammatory bacteria as responsible for releasing substances which aggravates the level of systemic inflammation [22] related to the intestinal disorder of autoimmune diseases [23-25].

Most of human infections are caused by opportunist pathogens that typically compose patient's normal microbiota, when there is significant amount of these pathogenic bacteria a disorder in the natural microbiota can be induced, thus circumventing the defense mechanisms and generating clinical symptoms [26]. The mucous immunological system is responsible for eliminating pathogens, therefore an inadequate immune response imbalances intestinal homeostasis, triggers dysbiosis and contributes to local and systemic inflammation as well as metabolic dysfunction [27].

Patients with SLE in activity present specific dysbiosis in microbiota and its related metabolic pathways [21] as a consequence of altered immunological function [3]. Therefore, changes in balanced microbiota composition, i.e. dysbiosis, may play an important role in promoting chronic inflammation in autoimmune diseases [24, 25] resulting in exacerbation, rapid progression, and disease worsening [28].

In relation to anti-inflammatory bacteria found in this review, it was observed decrease mainly in the phylum Tenericutes and Mollicutes, responsible for the modulation of the immune system. These types of bacteria can induce regulatory $\mathrm{T}$ cells, allowing the host to tolerate the amount of antigens in the intestine, thus preventing inflammation [29]. In addition, anti-inflammatory bacteria ferment carbohydrate, releasing butyrate, a fatty acid able to inhibit the production of pro-inflammatory cytokines, such as IL-12 and TNF- $\alpha$ [30].

When the interaction between anti and proinflammatory bacteria is altered, resulting in disruption of homeostasis, there is a dysbiosis [29]. This may result in local infection, inflammation and invasiveness [31] as well as complications that may lead SLE to the active condition. This is in line with researches that support that many autoimmune diseases, including SLE, were associated with intestinal microbiota dysbiosis, intestinal barrier dysfunction, and microbial translocation [32].

Concerning the pattern of intestinal bacteria in SLE in remission this review corroborates other studies related to imbalance in the ratio between Bacteroidetes and Firmicutes [31]. Approximately $90 \%$ of bacterial microbiota is composed of these two genera, which act in host metabolism and immunity [22], and their disproportion is correlated with clinical conditions [33]. Firmicutes are essential in the absorption of fatty acids and energy from carbohydrates while Bacteroidetes play a role in the absorption of polysaccharides [28].

Therefore, although another research indicates that microbiota composition in SLE post-treatment is similar to healthy control groups [19], SLE patients present Firmicutes/Bacteroidetes ratio next to 2.5 times lower [28]. This shows changes in intestinal microbiota may be pointed out even in SLE in remission [31], demonstrating association between dysbiosis and lupus [28].

Regarding differences in intestinal bacteria patterns, it was observed reduction in anti-inflammatory bacteria and enrichment of the pro-inflammatory ones in patients with SLE in activity when compared with those in remission [21]. This emphasizes that although they present similar diversity [21], the microbiota profile is different between both groups.

The relationship between microbiota and autoimmune diseases is relatively recent, so few studies (just five) were eligible to this systematic review, identifying investigation gaps. It is necessary in-depth studies to provide better understanding of aspects related not only to 
etiopathogenesis but also to the inflammatory process during SLE progression.

However, the main characteristic of this study was to raise an issue that has been insufficiently studied in literature. The results presented herein may be a source of encouragement for future studies focused on microbiota as a biomarker of activity in SLE, supporting medical community to elaborate investigation sequences and disease treatment.

The limitations of this review include the low number of SLE patients (288) and methodological diversity related to gender, some considered male and female patients while others prioritized female.

\section{Conclusion}

This systematic review evidenced representative microbiota patterns in SLE in activity, with greater amount of pathogenic bacteria and reduction of commensal bacteria, therefore indicating that there may be a relation between intestinal microbiota dysbiosis and disease activity. Besides, differences concerning intestinal microbiota pattern between SLE in activity and in remission were presented.

\section{Abbreviations}

ACR: American College of Rheumatology; EULAR: European League Against Rheumatism; GRADE: Grading of Recommendations, Assessment, Development and Evaluations; MeSH: Medical Subject Headings; PECO: Population, Exposure, Comparator and Outcome; PRISMA: Preferred Reporting Items for Systematic Reviews and Meta-Analyses; PROSPERO: International prospective register of systematic reviews; SLE: Systemic Lupus Erythematosus; SLEDAI: Systemic Lupus Erythematosus Disease Activity; SLICC: Systemic Lupus International Collaborating Clinic

\section{Acknowledgements}

We thank Capes for the doctorate degree scholarship of A.T.O. Rezende.

\section{Authors' contributions}

ATOR and JRP: outline development, paper writing, contribution to the methodologic aspect, database searches, and data analysis. MRF and NAS: manuscript preparation guidance, concept creation, and article design (objectives, theme and title). ATOR, JRP, MRF and NAS: reading and approval of the final manuscript.

\section{Funding}

Not applicable.

\section{Availability of data and materials}

Data sharing is not applicable to this protocol and no datasets were generated or analyzed.

\section{Declarations}

\section{Ethics approval and consent to participate}

Ethical approval was not required for this study, as the data used comprises of peer-reviewed publications and information that could identify the subjects of the original studies was not included.

\section{Consent for publication}

Not applicable.

\section{Competing interests}

All authors declare that they have no competing interests.

\section{Author details}

${ }^{1}$ Postgraduate Program in Health Sciences, School of Medicine of the Universidade Federal de Goiás (UFG), Goiânia, Brazil. ²Department of Orthopedics/Traumatology, School of Medicine of the Universidade Federal de Goiás (UFG), Goiânia, Brazil. ${ }^{3}$ Rheumatology Service of Hospital das Clínicas, School of Medicine of the Universidade Federal de Goiás (UFG), Goiânia, Brazil.

Received: 8 March 2021 Accepted: 20 June 2021

Published online: 02 July 2021

\section{References}

1. Esmaeili S-A, Mahmoudi M, Momtazi AA, Sahebkar A, Doulabi H, Rastin M. Tolerogenic probiotics: potential immunoregulators in systemic lupus erythematosus. J Cell Physiol. 2017;232(8):1994-2007. https://doi.org/10.1 002/jcp.25748.

2. Zhang H, Liao X, Sparks JB, Luo XM. Dinâmica da microbiota intestinal em auto-imune lúpus. Appl Environ Microbiol. 2014;80(24):7551-60. https://doi. org/10.1128/AEM.02676-14.

3. Hevia A, Milani C, López P, Cuervo A, Arboleya S, Duranti S, et al. Intestinal dysbiosis associated with systemic lupus erythematosus. MBio. 2014;5(5).

4. López P, Sánchez B, Margolles A, Suárez A. Intestinal dysbiosis in systemic lupus erythematosus: cause or consequence? Curr Opin Rheumatol. 2016; 28(5):515-22. https://doi.org/10.1097/BOR.0000000000000309.

5. González S, Gutiérrez-Díaz I, López P, Suárez A, Fernández-Navarro T, Sánchez BMA. Microbiota and oxidant-antioxidant balance in systemic lupus erythematosus. Nutr Hosp. 2017;34(4):934-41. https://doi.org/10.20960/nh.54 6.

6. Neuman $\mathrm{H}$, Koren $\mathrm{O}$. The gut microbiota: a possible factor influencing systemic lupus erythematosus. Curr Opin Rheumatol. 2017;29(4):374-7. https://doi.org/10.1097/BOR.0000000000000395.

7. Luo XM, Edwards MR, Mu Q, Yu Y, Vieson MD, Reilly CM, et al. Gut microbiota in human systemic lupus erythematosus and a mouse model of lupus. Appl Environ Microbiol. 2018;84(4):1-10.

8. Mu Q, Zhang H, Luo XMXM. SLE: Another Autoimmune Disorder Influenced by Microbes and Diet? Front Immunol. 2015;6(NOV):608.

9. López P, De Paz B, Rodríguez-Carrio J, Hevia A, Sánchez B, Margolles A, et al. Th17 responses and natural lgM antibodies are related to gut microbiota composition in systemic lupus erythematosus patients. Sci Rep. 2016;6:1-12.

10. Moher D, Shamseer L, Clarke M, Ghersi D, Liberatî A, Petticrew M, et al. Preferred reporting items for systematic review and meta-analysis protocols (PRISMA-P) 2015 statement. 2015.

11. Morgan RL, Whaley $P$, Thayer KASH. Identifying the PECO: a framework for formulating good questions to explore the association of environmental and other exposures with health outcomes. Environ Int. 2018;121(Pt 1): 1027-31. https://doi.org/10.1016/j.envint.2018.07.015.

12. Booth A, Clarke M, Dooley G, Ghersi D, Moher D, Petticrew M, et al. The nuts and bolts of PROSPERO: an international prospective register of systematic reviews. Syst Rev. 2012;1(1):2. https://doi.org/10.1186/2046-4 053-1-2.

13. Petri M, Orbai AM, Alarcõn GS, Gordon C, Merrill JT, Fortin PR, et al. Derivation and validation of the systemic lupus international collaborating clinics classification criteria for systemic lupus erythematosus. Arthritis Rheum. 2012;64(8):2677-86. https://doi.org/10.1002/art.34473.

14. Aringer M, Costenbader K, Daikh D, Brinks R, Mosca M, Ramsey-Goldman R, et al. 2019 European league against rheumatism/American College of Rheumatology Classification Criteria for systemic lupus erythematosus. Arthritis Rheum. 2019;71(9):1400-12. https://doi.org/10.1002/art.40930.

15. Parker B, Bruce IN. Clinical markers, metrics, indices, and clinical trials. Ninth Edit. Vol. 4, Dubois' Lupus Erythematosus and Related Syndromes. Elsevier Inc.; 2018. 614-630 p.

16. Downs SH, Black N. The feasibility of creating a checklist for the assessment of the methodological quality both of randomised and non-randomised studies of health care interventions. J Epidemiol Community Health. 1998; 52(6):377-84. https://doi.org/10.1136/jech.52.6.377.

17. Guyatt G, Oxman AD, Akl EA, Kunz R, Vist G, Brozek J, et al. GRADE guidelines. J Clin Epidemiol. 2011;64(4):383-94. https://doi.org/10.1016/j. jclinepi.2010.04.026.

18. Balshem H, Helfand M, Schünemann HJ, Oxman AD, Kunz R, Brozek J, et al. GRADE quidelines: 3. Rating the quality of evidence. J Clin Epidemiol. 2011; 64(4):401-6. https://doi.org/10.1016/j.jclinepi.2010.07.015. 
19. Chen B, Jia X, Xu J, Zhao L, Ji J, Wu B, et al. The gut microbiota of nontreated patients with SLE defines an autoimmunogenic and proinflammatory profile. Arthritis Rheum. 2020:2.

20. He Z, Shao T, Li H, Xie Z, Wen C. Alterations of the gut microbiome in Chinese patients with systemic lupus erythematosus. Gut Pathog. 2016;8(1): $1-7$.

21. Li Y, Wang H-F, Li X, Li H-X, Zhang Q, Zhou H-W, et al. Disordered intestinal microbes are associated with the activity of systemic lupus erythematosus. Clin Sci. 2019;133(7):821-38. https://doi.org/10.1042/CS20180841.

22. Tremaroli V, Bäckhed F. Functional interactions between the gut microbiota and host metabolism. Nature. 2012;489(7415):242-9. https://doi.org/10.1038/ nature11552.

23. van der Meulen TA, Harmsen HJM, Bootsma H, Spijkervet FKL, Kroese FGM, Vissink A. The microbiome-systemic diseases connection. Oral Dis. 2016; 22(8):719-34. https://doi.org/10.1111/odi.12472.

24. Lynch SV, Pedersen $\mathrm{O}$. The human intestinal microbiome in health and disease. N Engl J Med. 2016;375(24):2369-79. https://doi.org/10.1056/ NEJMra1600266.

25. Proal AD, Albert PJ, Marshall TG. The human microbiome and autoimmunity. Curr Opin Rheumatol. 2013;25(2):234-40. https://doi.org/10.1 097/BOR.0b013e32835cedbf.

26. Ara L, Castro S. Colonization of the intestinal microbiota and its influence on health host. Univ Ciências da Saúde, Brasília [Internet]. 2016;14(1):85-96. Available from: https://www.publicacoesacademicas.uniceub.br/cienciasa ude/article/view/3629

27. Shin N, Whon TW, Bae J. Proteobacteria: microbial signature of dysbiosis in gut microbiota. Trends Biotechnol [Internet]. 2015;1-8. Available from: https://www.sciencedirect.com/science/article/pii/S0167779915001390 (27).

28. Yacoub R, Jacob A, Wlaschin J, Mcgregor M, Richard J, Alexander JJ. Lupus: The microbiome angle. Immunobiology [Internet]. 2017; Available from: https:/www.sciencedirect.com/science/article/pii/S0171298517302115

29. Macdonald TT, Monteleone G. Regulation of homeostasis and inflammation in the intestine. YGAST [Internet]. 2011;140(6):1768-75 Available from: https://doi.org/10.1053/j.gastro.2011.02.047.

30. Magalhaes JG, Tattoli I, Girardin SE. The intestinal epithelial barrier : How to distinguish between the microbial flora and pathogens 2007;19:106-15. Available from: https://www.sciencedirect.com/science/article/pii/S10445323 07000024

31. De Luca F, Shoenfeld Y. The microbiome in autoimmune diseases. Clin Exp Immunol. 2019;195(1):74-85. https://doi.org/10.1111/cei.13158.

32. Mu Q, Kirby J, Reilly CM, Luo XM. Leaky gut as a danger signal for autoimmune diseases. Front Immunol. 2017;8(MAY):598.

33. Maranduba CMDC, De Castro SBR, De Souza GT, Rossato C, Da Guia FC, Valente MAS, et al. Intestinal microbiota as modulators of the immune system and neuroimmune system: Impact on the host health and homeostasis. J Immunol Res. 2015;2015.

\section{Publisher's Note}

Springer Nature remains neutral with regard to jurisdictional claims in published maps and institutional affiliations.

Ready to submit your research? Choose BMC and benefit from:

- fast, convenient online submission

- thorough peer review by experienced researchers in your field

- rapid publication on acceptance

- support for research data, including large and complex data types

- gold Open Access which fosters wider collaboration and increased citations

- maximum visibility for your research: over $100 \mathrm{M}$ website views per year

At $\mathrm{BMC}$, research is always in progress.

Learn more biomedcentral.com/submissions 